\title{
TRADUZIR É CATEGORIZAR: UM CASO DE TRADUÇÃO INTERLINGUÍSTICA ESPANHOL- PORTUGUÊS
}

\author{
Lucas Mario Dacuña Badaracco* \\ Universidade Federal de Pelotas
}

Mirian Rose Brum-de-Paula**

Universidade Federal de Pelotas

\begin{abstract}
Resumo: Neste artigo, investiga-se o modo como os processos de categorização e de proeminência ocorrem em fragmentos de Doze contos peregrinos, obra de García Márquez (2011). Para tanto, analisaram-se a versão original, em espanhol latino-americano, e uma versão traduzida, em português brasileiro (PB). Focam-se trechos em que o verbo poner (pôr) surge conjugado no particípio, na acepção de vestir-se, a fim de discutir o conteúdo semântico que as duas línguas expressam nessas situações. Haja vista que não há uma equivalência direta para puesto no $\mathrm{PB}$, quais seriam as opções do tradutor ao encontrar-se com uma estrutura do tipo El niño tiene los zapatos puestos (O menino está usando sapatos)? O que elas poderiam revelar sobre o aparato conceitual humano? Os níveis de catego-
\end{abstract}

\footnotetext{
* Mestrando na Universidade Federal de Pelotas (UFPel), Centro de Letras e Comunicação, Mestrando do Programa de Pós-Graduação em Letras - Área de Estudos da Linguagem (UFPel). Pelotas, Rio Grande do Sul, Brasil. E-mail: lucasbadaracco@hotmail.com

** Possui Graduação em Letras Português-Francês (UFSM -1987), Mestrado em Linguistique-Sémiotique-Communication (Université de Franche Comté - 1990) e Doutorado em Sciences du Langage Linguistique et Phonétique (Université de Paris X-Nanterre - 1998). Atualmente, é professora da Graduação e do Programa de Pós-Graduação em Letras da Universidade Federal de Pelotas (UFPel). Pelotas, Rio Grande do Sul, Brasil. E-mail: brumdepaula@yahoo.fr
} 
rização teriam as mesmas especificidade e distintividade na língua-fonte e na língua-alvo? Quais informações deixariam de ser expressas e quais se tornariam explícitas após um texto ser traduzido? Com base nas propostas de Rosch $(1975$; 1978) e Lakoff (1987), constataram-se diferenças que interessam à tradução.

Palavras-chave: Tradução. Categorização. Equivalência.

\title{
TRANSLATING IS CATEGORIZING: A CASE OF INTERLINGUAL TRANSLATION SPANISH- PORTUGUESE
}

\begin{abstract}
This paper investigates how the processes of categorization and prominence occur in excerpts of Strange Pilgrims, a title by García Márquez (2011). Seeking this, the original version, written in Latin American Spanish, and a translated one, written in Brazilian Portuguese (BP), were analyzed. The focus was on excerpts in which the verb poner (to put) arises as a participle, with the acceptation of to get dressed. The aim is to discuss the semantic content that both languages reveal in these situations. Considering there is not a single equivalent in BP, which would be the translator's options whenever appears an utterance like El niño tiene los zapatos puestos (The boy is wearing shoes)? What would they unveil about general properties of human conceptualization? Would the categorization levels have the same specificity and distinctiveness in the source language and the target language? Which kinds of information would fade away or come into sight from a translated text? Based upon Rosch's $(1975 ; 1978)$ and Lakoff's (1987) proposals, this work verifies differences that concern translation studies.
\end{abstract}

Keywords: Translation. Categorization. Equivalence.

No presente artigo, objetiva-se promover a discussão sobre processos e produtos que envolvem o fazer tradutório. A dissociação que se realiza entre fundo e forma ou, em outras palavras, entre conteúdo e expressão é, aqui, revisitada. Parte-se da ideia da não igualdade de significado entre o que foi originalmente engendrado na língua-fonte e o que ressurge na língua-alvo. $\mathrm{O}$ tradutor, que faz leituras minuciosas e que confronta línguas e culturas, acaba, inelutavelmente, recriando textos. Acredita-se, desse modo, não ser possível reconstituir o exato mesmo sentido de diferentes maneiras, 
pois fundo e forma estariam intimamente associados. Alterações na forma causariam, pois, mudanças de sentido que a tradução e os procedimentos que consistem em reportar um mesmo conteúdo de outro modo (como a paráfrase ou a sinonímia) não reproduziriam.

Em publicação composta por questões endereçadas a tradutores, Benedetti e Sobral (2003) destacam diversos pontos de vista sobre a leitura, sobre o ato interpretativo e sobre a recriação de textos. Considerando experiências advindas de trabalhos e pesquisas realizados com duas línguas em contato, muitos tradutores concebem a leitura, a produção e a criação como tarefas indissociáveis. Segundo Heloísa Barbosa, por exemplo, o "tradutor lê, processa e cria textos" (p.65). Para Mário Laranjeira, o "tradutor literário é um escritor" (p.121) e um "criador" (p.123). Maria Gonçalves, por sua vez, sublinha que "[...] uma nova tradução do mesmo texto é, digamos assim, uma outra obra” (p.112). Enfim, Vera Pereira evidencia que um "mesmo texto traduzido por pessoas diferentes nunca parece igual" (p.149).

Uma leitura atenta do texto de partida e de sua tradução desvenda descompassos sutis. De fato, percebem-se como semanticamente desiguais. Mas por que razão redizer implica transformar? De que modo isso ocorre? Embora diferente, o texto alvo parece o texto original. Então, afinal, que reorganizações ocorrem entre essas duas produções e que impacto produzem na construção do sentido? O que é mantido e o que é reconfigurado?

Para refletir e discutir sobre essas questões, comparam-se duas línguas neste estudo: o espanhol latino-americano e o português brasileiro (PB). O corpus analisado é composto por dados de língua escrita literária, retirados da obra Doze contos peregrinos (GARCÍA MÁRQUEZ, 2011). Focaliza-se o modo como a estrutura nominal (pertencente à categoria roupa) + pôr (particípio), empregada em espanhol, é traduzida para o português (p.ex.: Él tiene las botas puestas ou Él se había puesto las botas). Nas análises, recorre-se a procedimentos provenientes da linguística cognitiva e destacam-se os conceitos de categorização, proeminência e especificidade. 
Este artigo organiza-se em três seções: Uma linguística de cunho cognitivo, Noções sobre categorização e Processos cognitivos na tradução. Na primeira, dá-se um panorama sobre a vertente denominada linguística cognitiva, na qual se buscou o suporte teórico para este trabalho. Na segunda, por sua vez, introduz-se o conceito de categorização em uma perspectiva cognitivista, retomando pressupostos de Rosch (1978) e Lakoff (1987). Na terceira, por fim, analisam-se trechos da obra Doze contos peregrinos, do escritor colombiano Gabriel García Márquez. O objetivo é sinalizar e discutir diferenças de sentido entre a versão original, escrita em espanhol latino-americano, e a versão traduzida para o PB, em especial, no que tange a uma forma da língua de partida (puesto) que apresenta diversas possibilidades de tradução na língua de chegada.

\section{Uma linguística de cunho cognitivo}

Adotar o paradigma teórico intitulado linguística cognitiva implica considerar conhecimentos globais disponíveis - estruturais, contextuais, enciclopédicos - na construção do significado. Implica, também, analisar como esses conhecimentos são adquiridos, organizados e colocados em funcionamento. Segundo Fuchs (2004), as questões propostas dizem respeito à arquitetura estrutural dos conhecimentos linguísticos - ou seja, aos tipos e níveis dos diferentes conhecimentos interiorizados -, à arquitetura funcional desses conhecimentos - ou ao modo como estão organizados no cérebro humano -, à dinâmica da linguagem - à variabilidade linguística, principalmente, e ao funcionamento simbólico do espírito humano - ou, mais precisamente, aos laços existentes entre a linguagem e as outras faculdades humanas.

Dentre as novas perspectivas que surgiram sob essa etiqueta, destacaram-se, em território norte-americano, a corrente das gramáticas cognitivas (LAKOFF, 1980; LANGACKER, 1987; TALMY, 2000) e a abordagem neo-funcionalista (GIVÓN, 1989). $\mathrm{Na}$ Europa, a teoria das operações predicativas e enunciativas 
(CULIOLI et al., 1992) trata questões similares, ressaltando aspectos semântico-pragmáticos. Mas o que essas vertentes possuem em comum? Todas habitam margem oposta à gerativa. A concepção de linguagem e as hipóteses que compartilham as distanciam daquelas defendidas por Chomsky, Fodor (1983) e Pinker (2002), pois se baseiam em corpora textuais; adotam procedimentos indutivos; empregam práticas de cunho interacionista e construtivista; elegem a semântica como foco principal dos trabalhos; acreditam que a atividade linguageira é regida por mecanismos cognitivos gerais; interessam-se pela inter-relação entre forma e significado; retomam discussões sobre o vínculo existente entre língua, cultura e pensamento; convergem acerca do papel da percepção visual e da experiência sensório-motora na compreensão da estrutura semântica da linguagem; interessam-se pelas categorizações inscritas nos diferentes sistemas ou registros linguísticos e investigam a linguagem em uso; entre outras diferenças e ambições. A linguagem adquire, nessas novas abordagens, aspectos emergentistas e as modelizações propostas recorrem, consequentemente, à geometria, aos sistemas dinâmicos, ao conexionismo.

\section{Noções sobre categorização}

Tanto entidades do mundo (reais ou imaginárias; animadas ou inanimadas), suas ações, seus atributos e seus estados, como suas localizações no tempo e no espaço, são informações que podem ser arquivadas na memória e, a todo instante, resgatadas. Durante a fala, para que a comunicação se estabeleça, elas necessitam emergir. Assim, de uma maneira natural, automática e, aparentemente, simples, ideias surgem, comentários tecem-se e pensamentos ocorrem, transformando-se em fala articulada. Para que isso seja possível, a diversidade do ambiente físico e social, percebida por meio dos sentidos, é categorizada, ou seja, é estruturada e organizada de modo a reduzir a complexidade do mundo. Desse modo, uma mesma etiqueta pode nomear coisas diferentes. A categorização 
é, pois, uma operação mental central, essencial, sem a qual "cada objeto ou acontecimento seria apreendido como único e as generalizações seriam impossíveis" (VAUCLAIR, 2008, p.155). Lakoff (1987, p.06), no mesmo sentido, afirma que "sem a habilidade para categorizar, nós [os seres humanos] não poderíamos nem mesmo funcionar, fosse no mundo físico, fosse nas nossas vidas sociais e intelectuais.". O modo como a mente humana distribui elementos em categorias, entretanto, tem algumas peculiaridades. Uma delas é que os membros categoriais podem ser julgados por falantes como mais ideais (exemplares prototípicos) ou como menos ideais (exemplares radiais). Rosch (1978) chama esse fenômeno, que emerge da natureza dos modelos cognitivos, de efeito prototípico. A partir dele, nota-se que o pertencimento de elementos a categorias é, muitas vezes, gradativo. Destaca-se, ainda, que

entre protótipos e fronteiras categoriais há membros intermediários, organizados em termos de uma escala de prototipicidade. A organização categorial envolve desde representantes mais centrais, com suficiente similaridade ao protótipo, até representantes muito periféricos, que constituem efeitos do protótipo e apresentam poucos traços em comum com o núcleo categorial. (FERRARI, 2011, p.41).

Lakoff (1987) afirma que esse recente modelo de categorização (do paradigma experiencialista) opõe-se ao modelo tradicional (do paradigma objetivista). O modelo clássico foi amplamente aceito durante um longo período dos estudos linguísticos, tendo um status de verdade inquestionável. Nele, as categorias são (a) caracterizadas somente pelas propriedades compartilhadas entre seus membros; (b) independentes da natureza corpórea dos seres que categorizam; (c) desprovidas de recursos da imaginação (como metáfora, metonímia ou imagética) para conceber-se. Ao contrário, no novo modelo de categorização, as experiências corpóreas e o modo como se usam os recursos da imaginação são centrais para explicar 
como o ser humano constrói categorias, uma vez que elas não são dadas no mundo. Neste artigo, é essa visão experiencialista que serve como base à descrição e à explicação dos dados linguísticos do português e do espanhol.

As hipóteses do experiencialismo encontram respaldo em resultados de diversas pesquisas desenvolvidas na segunda metade do século XX. A primeira maior ruptura, que orientou investigações posteriores, em relação ao modelo clássico foi o estudo de Wittgenstein (1953 apud LAKOFF, 1987), no qual se lançou uma noção importante para a literatura das ciências cognitivas. Se as categorias tivessem fronteiras precisas e seus membros fossem agrupados com base em propriedades comuns, como explicar o exemplo de jogo? Haveria uma propriedade compartilhada por todos os jogos? Há os que envolvem apenas diversão, os que requerem sorte, os que têm competição, os que demandam habilidade. Embora não haja um conjunto de propriedades compartilhadas pelos jogos, a categoria é unida por aquilo que o autor chama de semelhanças de família. Membros de uma família são parecidos entre si de várias formas: eles podem compartilhar a mesma estrutura ou as mesmas características faciais, a mesma cor de cabelo ou de olhos, o mesmo temperamento etc. Entretanto, não existe um conjunto de traços que deva obrigatoriamente ser partilhado por todos os membros de uma família. Os jogos, nesse sentido, são como famílias. Xadrez e damas envolvem competição, habilidade e uso de estratégias a longo prazo. Xadrez e pôquer envolvem competição. Pôquer e truco são jogos de carta. Em suma, jogos, assim como membros de família, são similares entre si de formas bastante diversas. São essas semelhanças, e não um único conjunto bem definido de propriedades comuns, as que fazem de jogo uma categoria.

\section{Processos cognitivos na tradução}

A tradução interlinguística envolve conhecimentos acerca da gramática das línguas de partida e de chegada, dos ambientes em 
que essas línguas são usadas, das culturas que elas representam. Além disso, exige ao tradutor visões distintas sobre mesmos objetos, uma vez que cada sistema linguístico é um modo de representação único do mundo. Os símbolos linguísticos, nesse sentido, incorporam "[...] os meios pelos quais as gerações anteriores de seres humanos de um grupo social consideraram proveitoso categorizar e interpretar o mundo para fins de comunicação interpessoal." (TOMASELLO, 2003, p.11). As diferenças que sobressaem entre um texto traduzido e um original, em alguns casos, resultam dessas divergências conceptuais e são, por isso, inescapáveis. Nesta seção, abordam-se dois tópicos que servem de exemplo a tal afirmação e que se inter-relacionam no momento em que se traduz, para o $\mathrm{PB}$, o particípio puesto, do espanhol: a proeminência relativa e a categorização.

\subsection{A proeminência relativa}

Leia-se o seguinte trecho do conto A luz é como a água no original (1) e na tradução ao PB (2):

(1) "Al final del corredor, flotando entre dos aguas, Totó estaba sentado en la popa del bote, aferrado a los remos y con la máscara puesta, buscando el faro del puerto hasta donde le alcanzó el aire de los tanques [...]";

(2) "No final do corredor, flutuando entre duas águas, Totó estava sentado na popa do bote, agarrado aos remos e com a máscara no rosto, buscando o farol do porto até o momento em que houve ar nos tanques de oxigênio [...]". ${ }^{1}$

As diferenças do trecho traduzido em relação ao original, talvez, sejam sutis quanto ao significado, mas possam revelar aspectos interessantes sobre a organização gramatical de cada língua. Enquanto, em (1), o particípio puesta informa que o objeto (a más- 
cara) está sendo usado pela entidade (Totó); em (2), o adjunto (no rosto) indica a localização espacial do objeto na entidade. No que respeita a informações explícitas ou inferidas, a impossibilidade de traduzir o particípio do espanhol por um em português implica algumas mudanças. Em (1), explicita-se o processo ocorrido (pôr) e o estado final (puesto), inferindo-se em que lugar da entidade a máscara se encontra (no rosto); em (2), por sua vez, há uma inversão: explicita-se o locativo, inferindo-se o processo ocorrido e o estado final. ${ }^{2}$

A discrepância na organização gramatical permite chegar a um ponto comum nas duas línguas. Nos dois trechos, a proeminência relativa de elementos explicitamente mencionados ressalta aspectos diferentes. Em (1), por exemplo, no rosto é uma informação subjacente a máscara puesta. Seria redundante ao falante de espanhol, por exemplo, a combinação máscara puesta en el rostro. Em (2), embora inexista tal redundância, seria possível omitir no rosto sem incorrer em um enunciado inaceitável no PB. A respeito desses casos, afirma-se que

[...] podem ser ilustrados pelo contraste semântico entre pares de expressões como: triângulo vs. polígono de três lados; alcatra vs. carne retirada da parte traseira do boi; colher vs. utensílio culinário utilizado pela civilização ocidental moderna na alimentação, para degustação de cremes e sopas. (FERRARI, 2011, p.66, grifos da autora).

Embora apresentem conteúdos semânticos equivalentes, os pares contrastam, na medida em que "[...] o segundo membro de cada caso menciona explicitamente certos componentes semânticos, tornando-os mais proeminentes do que normalmente seriam." (FERRARI, 2011, p.67). Passando do nível lexical ao sintático, portanto, ter-se-ia o par máscara puesta vs. máscara no rosto. Mas por que a tradução não recorreu ao verbo vestir, como em outros casos? Eis um exemplo do conto Boa viagem, senhor presidente: 
(3) "Se había puesto la bata africana de sus noches de fiesta y sus collares y pulseras de santería [...]";

(4) "Havia vestido a túnica africana de suas noites de festa e seus colares e pulseiras de candomblé [...]”.

O particípio de (3), ao contrário do de (1), é verbal e não nominal. Conforme Perini (2010), no PB, todos os verbos teriam particípio verbal, porém nem sempre teriam particípio nominal. ${ }^{3}$ O primeiro tipo faria parte do verbo primitivo, uma vez que nele se percebem as regularidades morfológicas características da classe dos verbos. O segundo tipo, por seu turno, aproximar-se-ia da classe dos adjetivos, haja vista que tem forma verbal irregular e significado, muitas vezes, independente do verbo que o originou. Explica-se, desse modo, um dos motivos pelos quais não se poderia utilizar vestido para traduzir (1): no PB, vestir tem particípio verbal, mas não nominal. Haveria, ainda, outra razão, que perpassaria o âmbito gramatical em direção ao cognitivo.

\subsection{Categorizações presentes na construção ponerse ropa}

No espanhol, de acordo com Ibarretxe-Antuñano e Valenzuela (2012, p.18), o verbo pôr (poner) tem diferentes acepções (colocar, contar, supor, escrever, instalar...) e utiliza-se não somente em várias construções (transitiva, bitransitiva, pronominal...), mas também em diferentes colocações (pôr a mesa, pôr chifres...). Um dos usos é a combinação ponerse ropa, na qual há a acepção de colocar e na qual se tem uma construção pronominal. No entanto, ao traduzir-se esse sintagma para o $\mathrm{PB}$, algumas formas verbais impossibilitam uma tradução por pôr roupa (uma alternativa mais literal, conquanto o verbo não seja pronominal como no espanhol). Um exemplo é o uso em espanhol de pôr na forma de particípio nominal, qualificando alguma peça de vestuário, como no enunciado (1). Assim, da ausência de um particípio nominal para pôr no PB pode derivar a tradução (2), corrente na língua. 
No PB, atente-se que não é aleatório o complemento que acompanha o processo vestir (uma das opções de tradução de poner). Seriam bastante incomuns, por exemplo, as combinações a moça vestiu uma pá ou aquele rapaz vestiu um prato. Nem pá nem prato fazem parte da categoria roupa, que seria composta por elementos como camiseta, calças, meia, moletom. E máscara, nos trechos (1) e (2)? Inserir-se-ia nessa categoria? Pela teoria de protótipos e de categorias de nível básico, assim como boné, pulseira, relógio ou anel, máscara integraria uma categoria radial dentro das roupas. Camiseta ou moletom, diferentemente, comporiam uma categoria prototípica. Em um esquema visual, camiseta (1), meia (2) e máscara (3) distribuir-se-iam do seguinte modo:

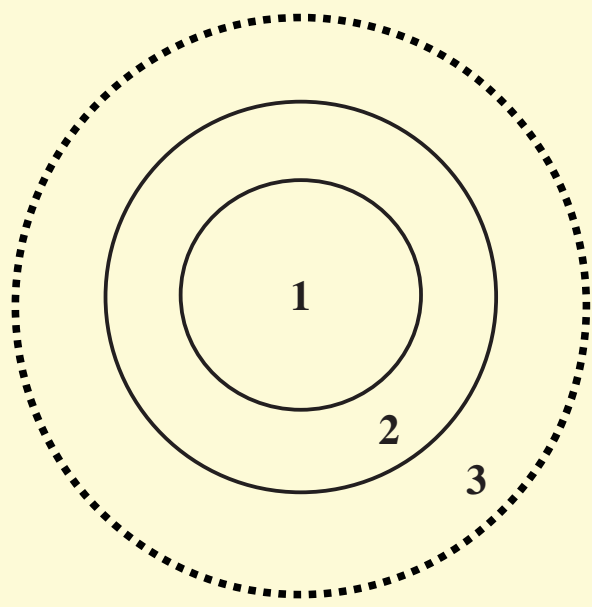

Figura 1 - Elementos da categoria roupa

Camiseta (1) estaria no núcleo categorial; meia (2), por sua vez, situar-se-ia próximo do núcleo, porém não seria um dos protótipos da categoria; máscara (3), por fim, localizar-se-ia na fronteira categorial, uma zona radial. Ferrari (2011, p.38-39), partindo de estudos cujo foco era o fenômeno da categorização, lista duas con- 
clusões que interessam: "as categorias não representam divisões arbitrárias de entidades do mundo, mas surgem baseadas em capacidades cognitivas da mente humana" e "as fronteiras das categorias cognitivas são imprecisas, de modo que categorias vizinhas não são separadas por limites rígidos, mas há uma zona de intersecção". Se essas afirmações forem aceitas, podem-se justificar escolhas no âmbito da tradução por meio de pressupostos cognitivistas.

Máscara (uma categoria de nível básico), por exemplo, pode conceber-se fora do domínio de roupa (uma categoria superordenada). Isso é possível porque as categorias superordenadas e subordinadas seriam, nos termos de Brown (1965 apud LAKOFF, 1987, p.32), "frutos da imaginação". ${ }^{4} \mathrm{O}$ fato de poder vestir camisetas, calças ou meias, mas apenas usar máscaras ou óculos permitiria propor que disfarces e acessórios opõem-se a roupas. Por isso, a tradução de poner por vestir apenas é preferida se o objeto integra a categoria roupa, como em (3).

A respeito dos sistemas categoriais, propõe-se que teriam duas dimensões, uma vertical e outra horizontal.

A dimensão vertical diz respeito ao nível de especificidade da categoria - a dimensão na qual os termos collie, cachorro, mamífero, animal e ser vivo variam. A dimensão horizontal diz respeito à segmentação das categorias no mesmo nível de especificidade - a dimensão na qual cachorro, gato, carro, ônibus, cadeira e sofá variam. (ROSCH, 1978, p.30). ${ }^{5}$

Nessa perspectiva, a categoria superordenada de máscara poderia ser disfarce, um nível mais abrangente. Diferentemente, a de túnica - do enunciado (4) - seria roupa. Assim, opor-se-iam as categorias disfarce e roupa, as quais concorreriam no mesmo eixo horizontal, juntamente com a de acessórios. 


\begin{tabular}{l|l|l|l}
\hline SUPERORDENADO & Roupa & Disfarce & Acessório \\
\hline NÍVEL BÁSICO & Túnica & Máscara & Óculos \\
\hline
\end{tabular}

Tabela 1 - Níveis categoriais superordenado e básico

Em um dos experimentos realizados por Rosch (1975), pediu-se a sujeitos de pesquisa falantes de língua inglesa que pontuassem membros de diversas categorias (veículos, armas, aves etc.) como bons ou maus representantes do grupo em que se inseriam. Os informantes atribuíam notas de um (01) a sete (07): a nota um usava-se quando o elemento fosse considerado um bom exemplar da categoria; a nota sete, quando fosse considerado um mau exemplar. Na categoria roupa, chapéu obteve 4.20 de média; relógio, 6.15; bracelete, 6.24, o que confirma o status periférico desses elementos em relação a calças (1.12), vestido (1.14) ou saia (1.21). O fato de não haver nenhum representante de disfarce também indicaria um status marginal dessa categoria se for subordinada à de roupa .

Ao ler-se a tradução de um trecho do conto Dezessete ingleses envenenados, a discussão concernente à categorização de objetos estende-se à da categorização dos processos pôr e vestir. Além de (3) e (4), há outros fragmentos passíveis de análise.

(5) "Empinada por encima del hombro de los curiosos, la señora Prudencia Linero volvió a ver entonces a los turistas ingleses. Los estaban sacando en camillas, uno por uno, y todos estaban inmóviles y dignos, y seguían pareciendo uno solo varias veces repetido con el traje formal que se habían puesto para la cena: pantalón de franela, corbata de rayas diagonales, y la chaqueta oscura con el escudo del Trinity College bordado en el bolsillo del pecho.";

(6) "Empinada por cima do ombro dos curiosos, a senhora Prudencia Linero voltou a ver então os turistas ingleses. Estavam sendo retirados em macas, um a um, e estavam todos imóveis e dignos, e continuavam parecendo um só várias 
vezes repetido com a roupa formal que haviam vestido para o jantar: calças de flanela, gravata de listras diagonais, e a jaqueta escura com o escudo do Trinity College bordado no bolso do peito.”.

Assim como (4), a tradução (6) opta por vestir para ponerse. Além disso, enquanto na língua-fonte se lê traje formal, na língua-alvo, ocorre roupa formal. A figura do tradutor percebe-se por uma alteração no nível de especificidade dessas expressões: traje, no espanhol, é mais específico que roupa no português, ao passo que ponerse é menos específico que vestir. ${ }^{6}$ Ponerse (do espanhol) e pôr (do português) são processos cujo uso não se impede pelos objetos das categorias de disfarces ou acessórios. Vestir (do espanhol e do português), contudo, restringe-se a objetos da categoria roupa, o que se reproduz nas próprias traduções. Uma evidência estaria nos juízos distintos que se fazem das combinações vestir calças, vestir meias, vestir chapéu ou vestir cadeira, os quais decorreriam da compatibilidade entre processo e objeto.

Note-se, ainda, que, em espanhol, vestir e disfrazarse seriam englobados por ponerse. Do mesmo modo, em português, haveria a mesma relação entre vestir e disfarçar-se (processos mais específicos) e pôr (processo mais geral). Assim, ter-se-ia a seguinte organização:

\begin{tabular}{l|l|l}
\hline LÍNGUA & Espanhol & Português \\
\hline NÍVEL SUPERIOR & Ponerse & Pôr \\
\hline NÍVEL INFERIOR & Vestirse, disfrazarse & Vestir-se, disfarçar-se \\
\hline
\end{tabular}

Tabela 2 - Níveis superior e inferior de processos em espanhol e em português

Em suma, ao deparar-se com trechos similares a (1), (3) e (5) e ao valorizar a língua-alvo em detrimento da língua-fonte, o tradu- 
tor tem uma série de opções. Em muitos casos de tradução (talvez na grande maioria), no entanto, pode haver alteração de estruturas cognitivas: seja tornando explícitos sentidos antes latentes, seja tornando implícitos sentidos antes aparentes no texto.

Por meio do estudo da categorização em cada língua, permite-se não somente entender com mais acurácia os processos cognitivos envolvidos na tradução, como também prever as escolhas gramaticais da língua-alvo em determinadas situações. Desse modo, podem-se sistematizar as alternativas tradutórias, visando a discutir as vantagens e as desvantagens que cada uma pressupõe em diversos contextos prováveis. Tome-se, por exemplo, um trecho do conto Maria dos Prazeres:

(7) "No volvieron a hablar en todo el trayecto, pero también María dos Prazeres se sintió examinada de soslayo varias veces, y una vez más se dolió de seguir viva a su edad. Se sintió fea y compadecida, con la pañoleta de cocina que se había puesto en la cabeza de cualquier modo cuando empezó a llover, y el deplorable abrigo de otoño que no se le había ocurrido cambiar por estar pensando en la muerte.”.

A tradução do trecho negritado de (7) para o português, com base nas análises de (1), (3) e (5), é previsível, de certo modo. Ao assumir-se que o termo pañoleta de cocina (lenço de cozinha) estaria mais próximo de um acessório que de uma roupa, não se recorreria a vestir no PB. Ainda, uma vez que esse acessório não serve apenas para ser colocado na cabeça (como um chapéu, por exemplo), a combinação puesto en la cabeza não é redundante, mas, antes, necessária. Além disso, por haver uma estrutura de particípio verbal e não nominal, colocado ou posto são bem aceitos gramaticalmente. E, de fato, é assim que a tradução procede:

(8) "Não tornaram a falar em todo o trajeto, mas também Maria dos Prazeres sentiu-se examinada de soslaio várias 
vezes, e uma vez condoeu-se por continuar viva à sua idade. Sentiu-se feia e compadecida, com o lenço de cozinha que havia posto na cabeça de qualquer jeito quando começou a chover, e o deplorável sobretudo de outono que não tivera a ideia de trocar porque estava pensando na morte.".

No entanto, em outros tempos verbais, com uma construção gramatical diferente, a previsibilidade seria menor. No seguinte trecho hipotético, no presente do indicativo, por exemplo, cada alternativa do tradutor selecionaria elementos explicitamente mencionados ou categorias distintos:

(9) La profesora de mi hija siempre tiene los lentes puestos.

No enunciado acima, o nominal lentes (óculos) pressuporia o locativo (no rosto), elemento que a tradução para o PB poderia ou não revelar, a depender do contexto. ${ }^{7}$ Os falantes de espanhol entenderiam que a professora está usando o acessório (os óculos) da forma convencional, o que torna a tradução uma tarefa mais árdua do que se imagina. Como produzir o mesmo efeito de sentido? $\mathrm{Ou}$, melhor: é possível fazê-lo? Eis algumas alternativas:

(10) A professora da minha filha sempre está com os óculos (no rosto).

(11) A professora da minha filha sempre está de óculos.

(12) A professora da minha filha sempre está usando óculos.

(13) (?) A professora da minha filha sempre veste óculos.

Ressalte-se que não se descartam, categoricamente, outras realizações da sequência nominal (pertencente às categorias roupa, disfarce ou acessório) + pôr (particípio) na própria língua espanhola. Uma redundância como em el hombre tiene los lentes puestos en la cara pode ter um efeito cômico na comunicação, se essa for a intenção do falante. Nesse sentido, a aceitabilidade de um enunciado abstraído de intenções e de informações contextuais não é mensurável e, portanto, não entra em discussão. Nesse tópico, concorda-se 
com Jakobson (2010), quem defende que significados extraídos de operações metalinguísticas de falantes de uma determinada língua como língua materna seriam mais fidedignos que aqueles retirados de testes de aceitabilidade. Além disso, "as elipses e os anacolutos, inadmissíveis num estilo explícito e meticuloso, poderiam ser facilmente condenados por um informante, a despeito de seu uso coloquial, emotivo ou poético." (JAKOBSON, 2010, p.120). Da mesma forma, isso poderia acontecer com pleonasmos e com outras figuras de linguagem. Por isso, acredita-se que "[...] nunca se observa nos enunciados o sentido bruto ou inerente de uma unidade: os sentidos atribuídos a uma unidade são sempre o produto da interação que se estabelece com o seu cotexto." (DE VOGÜÉ; FRANCKEL; PAILLARD, 2011, p.25). Os trechos analisados neste artigo, a esse respeito, são sempre contextualizados linguisticamente e têm um valor semântico determinado na e pela obra Doze contos peregrinos.

\section{Considerações finais}

No presente trabalho, versou-se sobre duas línguas próximas tipologicamente, íntimas a ponto de compartilharem itens lexicais, construções gramaticais e história. Convivendo geograficamente lado a lado - tanto no velho mundo como no espaço latino-americano -, podem ser consideradas irmãs. A familiaridade e a proximidade entre ambas, contudo, não impedem que fatiem o universo de modo diverso. Como destaca Robert, para "ter acesso a um mesmo referente, as línguas constroem caminhos referenciais variáveis" (1997, p. 26). A discussão relativa aos trechos selecionados da obra Doze Contos Peregrinos busca servir como ponto de partida para futuras investigações no âmbito dos estudos da tradução. Apesar de tratar-se de duas línguas pouco distantes, o PB e o espanhol apresentam diferenças importantes que perpassam o puramente gramatical. As distintas traduções de um único elemento do espanhol (puesto) não deturpam o significado do original, uma 
vez que o leitor da língua-fonte e o leitor da língua-alvo, muito possivelmente, imaginam as mesmas cenas em (1) e (2), por exemplo. O que há de diferente é o modo de cada língua construir o sentido, o qual se apreende não somente por meio do saber linguístico, mas também por meio de outros mecanismos cognitivos que se manifestam na linguagem. Nesse aspecto, entra em jogo a habilidade de categorização: uma das mais básicas do pensamento, da percepção, da ação e da fala humanos.

Sempre que concebemos algo como um tipo de coisa, por exemplo, uma árvore, nós estamos categorizando. Quando raciocinamos sobre tipos de coisas - cadeiras, nações, doenças, emoções, qualquer tipo de coisa - nós empregamos categorias. (LAKOFF, 1987, p.05-06).

Com base na bibliografia das ciências cognitivas e nos exemplos discutidos neste artigo, sugere-se que uma das muitas habilidades que o tradutor deve ter é saber categorizar nas duas línguas. Levantar tal hipótese significa conceber a tradução como uma atividade essencialmente humana, de natureza criativa e não mecânica. Ao tradutor convém vestir a roupa do nativo, estar na sua pele, para que a opção entre ser fiel ou trair não seja fortuita. Quanto à máquina, conseguirá traduzir somente "[...] quando (1) tiver um corpo físico semelhante ao humano e (2) tiver capacidade de sentir." (BENEDETTI; SOBRAL, 2003, p.207). Que indivíduo senão um humano, afinal, seria capaz de entender os diferentes usos que a humanidade faz de máscaras, sobretudos ou sapatos? É possível reproduzir modos de representações categoriais que são frutos $d a$ imaginação (níveis superordenado e subordinado) em entidades desprovidas de sensibilidade corpórea e processamento linguístico-cognitivo dinâmico? 


\section{Notas}

1. Grifos nossos em todos os trechos da obra de García Márquez.

2. Slobin (1996, p.84), nesse sentido, cita um caso semelhante, que também envolve o uso do particípio, ao comparar relatos de crianças falantes de inglês e de espanhol. Para referir-se a uma cena em que há um menino em cima de uma árvore, na língua inglesa, preferem-se construções como “The boy climbed the tree", mas, na língua espanhola, ocorrem exemplos como "El niño está subido en el árbol”. No primeiro enunciado, explicita-se a trajetória (para cima, expressa por subir) e infere-se o estado final (em cima); no segundo, explicita-se o estado final e infere-se a trajetória. Essa diferença faria parte de uma característica mais geral no discurso de cada língua: o inglês tenderia a explicitar trajetórias e a inferir estados finais; o espanhol, a explicitar locativos e estados finais e a inferir trajetórias.

3. O mesmo ocorre na língua espanhola.

4. No original, "achievements of the imagination".

5. No original, "The vertical dimension concerns the level of inclusiveness of the category - the dimension along which the terms collie, dog, mammal, animal and living thing vary. The horizontal dimension concerns the segmentation of categories at the same level of inclusiveness - the dimension on which dog, cat, car, bus, chair and sofa vary.".

6. Na língua espanhola, existem os vocábulos ropa (roupa) e vestir (vestir), com acepções bastante similares aos equivalentes em português.

7. A explicitação do locativo seria necessária em certos contextos porque, em casos como o garoto está com a máscara, não se poderia depreender o processo omitido. Se o trecho for descontextualizado, o garoto poderia estar usando a máscara no rosto quanto apenas estar portando-a nas mãos. 


\section{Referências}

BENEDETTI, I. C.; SOBRAL, A. (Org.). Conversas com tradutores. São Paulo: Parábola, 2003.

CULIOLI, A. et al. La théorie d'Antoine Culioli. Paris: Ophrys, 1992

DE VOGÜÉ, S.; FRANCKEL, J.J.; PAILLARD, D. Linguagem e enunciação: representação, referenciação e regulação. São Paulo: Contexto, 2011.

FERRARI, L. Introdução à Linguística Cognitiva. São Paulo: Contexto, 2011.

FODOR, J. A. The Modularity of Mind. Cambridge: MIT Press, 1983.

FUCHS, C. La linguistique cognitive. Paris: Ophrys, 2004.

.; ROBERT, S. (Org.). Diversité des langues e representations cognitives. Paris: Ophrys, 1997.

García Márquez, G. Doce cuentos peregrinos. $18^{\mathrm{a}}$ ed. Buenos Aires: Debolsillo, 2011.

Record, 1992.

Doze contos peregrinos. Tradução de Eric Nepomuceno. Rio de Janeiro:

GIVÓN, T. Mind, code and context: Essays in Pragmatics. Hillsdale: Lawrence Erlbaum, 1989.

IBARRETXE-ANTUÑANO, I.; VALENZUELA, J. Lingüística Cognitiva: origen, principios y tendencias. In: . (Org.). Lingüística Cognitiva. Barcelona: Anthropos, 2012. p.13-28.

JAKOBSON, R. Linguística e comunicação. 22ª ed. São Paulo: Cultrix, 2010. 
LAKOFF, G. Women, fire and dangerous things: what categories reveal about the mind. Chicago: The University of Chicago Press, 1987.

; JOHNSON, M. Metaphors we live by. Chicago: The University of Chicago Press, 1980.

LANGACKER, R. W. Foundations of cognitive grammar: Theoretical Prerequisites. Stanford: Stanford University Press, 1987.

PERINI, M. A. Gramática do português brasileiro. São Paulo: Parábola, 2010.

PINKER, S. O instinto da linguagem: como a mente cria a linguagem. São Paulo: Martins Fontes, 2002.

ROBERT, S. Variation des représentations linguistiques: des unites à l'énoncé. In: FUCHS, C.; ROBERT, S. (Org.). Diversité des langues et représentations cognitives. Paris: Ophrys, 1997. p.25-39.

ROSCH, E. Cognitive representations of semantic categories. In: Journal of Experimental Psychology: General. v. 104, nº 3. 1975. p.192-23

. Principles of categorization. In: ROSCH, E.; LLOYD, B. B (Orgs.). Cognition and categorization. Hillsdale: Lawrence Erlbaum, 1978. p.27-48.

TALMY, L. Toward a cognitive semantics. Cambridge: MIT Press, 2000.

TOMASELLO, M. Origens culturais da aquisição do conhecimento humano. São Paulo: Martins Fontes, 2003.

VAUCLAIR, J. Desenvolvimento da criança do nascimento aos dois anos: motricidade, percepção, cognição. Lisboa: Instituto Piaget, 2008.

Recebido em: 17- 12-2014

Aceito em: 29/01/2015 